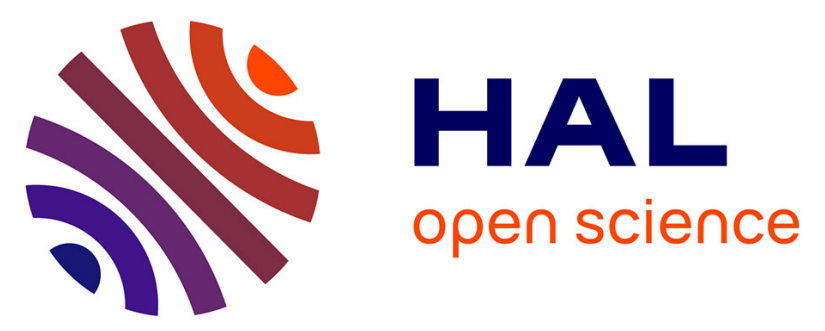

\title{
Dysfunctional d-aspartate metabolism in BTBR mouse model of idiopathic autism
}

\author{
Tommaso Nuzzo, Masae Sekine, Daniela Punzo, Mattia Miroballo, Masumi \\ Katane, Yasuaki Saitoh, Alberto Galbusera, Massimo Pasqualetti, Francesco \\ Errico, Alessandro Gozzi, et al.
}

\section{To cite this version:}

Tommaso Nuzzo, Masae Sekine, Daniela Punzo, Mattia Miroballo, Masumi Katane, et al.. Dysfunctional d-aspartate metabolism in BTBR mouse model of idiopathic autism. Biochimica et Biophysica Acta Proteins and Proteomics, 2020, 1868, 10.1016/j.bbapap.2020.140531 . hal-03089117

\section{HAL Id: hal-03089117 https://hal.science/hal-03089117}

Submitted on 27 Dec 2020

HAL is a multi-disciplinary open access archive for the deposit and dissemination of scientific research documents, whether they are published or not. The documents may come from teaching and research institutions in France or abroad, or from public or private research centers.
L'archive ouverte pluridisciplinaire HAL, est destinée au dépôt et à la diffusion de documents scientifiques de niveau recherche, publiés ou non, émanant des établissements d'enseignement et de recherche français ou étrangers, des laboratoires publics ou privés. 


\section{Journal Pre-proof}

Dysfunctional d-aspartate metabolism in BTBR mouse model of idiopathic autism

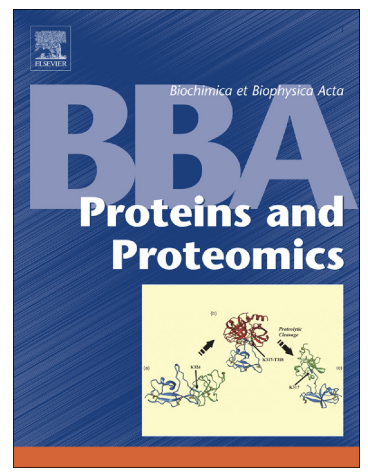

Tommaso Nuzzo, Masae Sekine, Daniela Punzo, Mattia Miroballo, Masumi Katane, Yasuaki Saitoh, Alberto Galbusera, Massimo Pasqualetti, Francesco Errico, Alessandro Gozzi, JeanPierre Mothet, Hiroshi Homma, Alessandro Usiello

PII: S1570-9639(20)30178-3

DOI: https://doi.org/10.1016/j.bbapap.2020.140531

Reference: BBAPAP 140531

To appear in: BBA - Proteins and Proteomics

Received date: 16 May 2020

Revised date: 22 July 2020

Accepted date: 31 July 2020

Please cite this article as: T. Nuzzo, M. Sekine, D. Punzo, et al., Dysfunctional d-aspartate metabolism in BTBR mouse model of idiopathic autism, BBA - Proteins and Proteomics (2020), https://doi.org/10.1016/j.bbapap.2020.140531

This is a PDF file of an article that has undergone enhancements after acceptance, such as the addition of a cover page and metadata, and formatting for readability, but it is not yet the definitive version of record. This version will undergo additional copyediting, typesetting and review before it is published in its final form, but we are providing this version to give early visibility of the article. Please note that, during the production process, errors may be discovered which could affect the content, and all legal disclaimers that apply to the journal pertain.

(C) 2020 Published by Elsevier. 


\section{Dysfunctional D-aspartate metabolism in BTBR mouse model of idiopathic autism}

Tommaso Nuzzo ${ }^{1}$, Masae Sekine ${ }^{2}$, Daniela Punzo ${ }^{3}$, Mattia Miroballo ${ }^{1}$, Masumi Katane ${ }^{2}$, Yasuaki Saitoh $^{2}$, Alberto Galbusera ${ }^{4}$, Massimo Pasqualetti ${ }^{5}$, Francesco Errico ${ }^{6}$, Alessandro Gozzi ${ }^{4}$, Jean-Pierre Mothet $^{7}$, Hiroshi Homma, ${ }^{2,}$, Alessandro Usiello, ${ }^{1,3,8, @ ~}$

${ }^{1}$ Translational Neuroscience Unit, IRCCS "Casa Sollievo della Sofferenza", San Giovanni Rotondo, Italy;

${ }^{2}$ Graduate School of Pharmaceutical Sciences, Kitasato University, Tokyo, Japan;

${ }^{3}$ CEINGE Biotecnologie Avanzate, Naples, Italy;

${ }^{4}$ Functional Neuroimaging Laboratory, Istituto Italiano di Tecnologia, Center for Neuroscience and Cognitive Systems, Rovereto (TN), Italy;

${ }^{5}$ Department of Biology, Unit of Cell and Developmental Biology University of Pisa, 56127 Pisa, Italy;

${ }^{6}$ Department of Agricultural Sciences, University of Naples "Feder' « II , Via Università, 100, 80055, Portici, Italy;

${ }^{7}$ Laboratoire LuMin, FRE 2036 CNRS, ENS Paris Saclay, U nivt sité Paris-Saclay, 91190 Gif-surYvette, France;

${ }^{8}$ Department of Environmental, Biological and Pharmacev'su. ${ }^{1}$ ¿ciences and Technologies, University of Campania "Luigi Vanvitelli", Caserta, Italy.

${ }^{\circledR}$ Corresponding authors:

Hiroshi Homma, Graduate School of Pharmaceutic a' S siences, Kitasato University, Tokyo, Japan. email: hommah@pharm.kitasato-u.ac.jp

Alessandro Usiello, Department of Envirc $1 \mathrm{~m} r$ ntal, Biological and Pharmaceutical Sciences and Technologies, University of Campania "Luigi "anvitelli", Via A. Vivaldi, 4, 81100 Caserta, Italy. email: usiello@ ceinge.unina.it.

\section{Current Affiliations:}

Tommaso Nuzzo, Department C Eıvironmental, Biological and Pharmaceutical Sciences and Technologies, University of Camp. nıa "Luigi Vanvitelli", Via A. Vivaldi, 4, 81100 Caserta, Italy. Daniela Punzo, Department ot Mi robiology \& Molecular Genetics, U1233 INSERM, Center for Epigenetics and Metabolism Un versity of California, Irvine, Irvine, CA 92697, USA.

Alessandro Usiello, since $\chi_{\lrcorner \mathrm{u}}$ is no longer affiliated with Translational Neuroscience Unit, IRCCS "Casa Sollievo della Sofferar za", San Giovanni Rotondo, Italy

\section{Abstract}

Background 
Autism spectrum disorders (ASD) comprise a heterogeneous group of neurodevelopmental conditions characterized by impairment in social interaction, deviance in communication, and repetitive behaviors. Dysfunctional ionotropic NMDA and AMPA receptors, and metabotropic glutamate receptor 5 activity at excitatory synapses has been recently linked to multiple forms of ASD. Despite emerging evidence showing that D-aspartate and D-serine are important neuromodulators of glutamatergic transmission, no systematic investigation on the occurrence of these D-amino acids in preclinical ASD models has been carried out.

\section{Methods}

Through HPLC and qPCR analyses we investigated D-asparu te and D-serine metabolism in the brain and serum of four ASD mouse models. These include BTL . mice, an idiopathic model of ASD, and Cntnap $^{-/}$, Shank $3^{-\sim}$, and $16 p 11.2^{+\sim}$ mice, three est'sli hed genetic mouse lines recapitulating high confidence ASD-associated mutations.

\section{Results}

Biochemical and gene expression marnin: ${ }_{i}$ Cntnap $^{-/}$, Shank $3^{-/}$, and $16 p 11.2^{+/-}$failed to find gross cerebral and serum alterations in D sspattate and D-serine metabolism. Conversely, we found a striking and stereoselective increased $n_{-\_} \cdot r$ artate content in the prefrontal cortex, hippocampus and serum of inbred BTBR mice. Consisı nt with biochemical assessments, in the same brain areas we also found a robust reduction in mRNA levels of D-aspartate oxidase, encoding the enzyme responsible for Daspartate catabolism, and an increased mRNA expression of serine racemase, which is partially involved in cerebral D-aspartate biosynthesis.

\section{Conclusions}

Our results demonstrated the presence of disrupted D-aspartate metabolism in a widely used animal model of idiopathic ASD.

\section{General Significance}


Overall, this work calls for a deeper investigation of D-amino acids in the etiopathology of ASD and related developmental disorders.

Keywords: D-aspartate, D-aspartate oxidase, NMDA receptors, D-serine, Autism Spectrum Disorder.

\section{Introduction}

Autism spectrum disorder (ASD) is characterized by severe an ${ }^{-} s$ ustained impairment in social interaction, deviance in communication, and repetitive bek vioıs $[1,2]$. The causes of ASD vary greatly, including both genetic and environmental facto- A remarkable preponderance of ASDassociated genetic mutations affect proteins mediati is, s naptic functions, such as $\mathrm{SH} 3$ and multiple ankyrin repeat domains 3 (SHANK3), conta tin associated protein-like (CNTNAP), neuroligins, and neurexins [3-6]. Other genetic aberratio. $\&$ associated with ASD include copy number variations (CNVs) in chromosomal loci 15q11-q13, '6r 11.2, and 22q11.21 [5, 7].

A large body of evidence points $a^{\prime}$ im $_{\vdash}$ aired glutamatergic signaling in ASD [8-14]. In keeping with this, clinical studies have ider. ${ }^{i}$ fir $\mathrm{d}$ several genetic variations in L-glutamate (L-Glu) ionotropic receptor NMDA type (NM글) subunit 2A and 2B (GRIN2A and GRIN2B), as well as in other genes of the metabotropic L-Glu receptor (mGluR) network in ASD patients [11, 12]. Moreover, positive and negative NMDAR modulators and mGluR5 antagonists have been shown to alleviate ASD symptoms in patients and normalize ASD-like phenotypes in animal models [11]. These results suggest that both hyper- and hypoactivation of these receptors might induce ASD-like symptoms. Altered NMDAR functions have been also reported in a number of rodent models of syndromic forms of ASD, including Shank $3^{\Delta \mathrm{C} / \Delta \mathrm{C}}$ mice, Neuroligin-3 ${ }^{\mathrm{R} 451 \mathrm{C}}$ knock-in mice, and $F m r 1^{-/-}$mice [15], as well as in mice and rats prenatally exposed to valproic acid [16, 17], a teratogen known to induce ASD in humans. 
Recently, several lines of evidence have shown that changes (e.g., availability, metabolism, and/or receptor activity) in neuroactive free amino acids may play a role in the pathogenesis and/or pharmacotherapy of severe psychiatric disorders characterized by a developmental origin (e.g., schizophrenia) and sharing symptoms with ASD, including cognitive and social interaction impairments [18-24]. Among these amino acids, free D-serine (D-Ser) and D-aspartate (D-Asp) act as co-agonist and agonist for NMDARs, respectively [25-27]. Moreover, D-Asp has also been shown to activate mGluR5-dependent transmission [28]. Remarkably, in maıt malian brain D-Asp display a peculiar time-dependent occurrence, since it is highly abundant $n_{1_{1}}$ it embryonic stages of life [2931]. D-Ser is synthesized de novo by serine racemase (SR, 132, 33], while the metabolic pathway responsible for D-Asp biosynthesis has not yet been clearly d. fined [34-36]. However, some evidence has shown that SR might contribute to endogenous ${ }^{-A}$ sp formation $[34,35]$. D-Ser and D-Asp are catabolized by two different peroxisomal er ryr es, D-amino acid oxidase (DAAO) [37, 38] and Daspartate oxidase (DDO) $[27,39]$, respectiv. ${ }^{\prime} y$. Although several studies indicate that D-Asp and D-Ser might be involved in the pathogenesic of nc ychiatric disorders such as schizophrenia [20, 27, 40-43], bipolar disorder [44, 45], and depı ssioı [46-48], the role of these D-amino acids in ASD has not yet been addressed. Here, for the $t_{1}+$ ime, we investigated the metabolism of D-Asp and D-Ser in the brain and serum of four we' - established animal models of ASD, including BTBR T+ Itpr3tf/J (BTBR) [49], Cntnap $2^{-/}[50]$, Shank3 $3^{-/}$[51], and 16p11.2 $2^{+-}$[52] mice.

\section{Materials and Methods}

\subsection{Animals and ethical statement}


Adult mice of the inbred strains C57BL/6J and BTBR along with Cntnap $2^{-/-}$, Shank $3^{-/}$, and $16 p 11.2^{+-}$ with their relative control "wild-type" breeding pairs were obtained from Jackson Laboratory (Bar Harbor, ME, USA). Animal studies were conducted in accordance with Italian Law (DL 26/2014, EU 63/2010, Ministero della Sanità, Roma) and recommendations outlined in the Guide for the Care and Use of Laboratory Animals of the National Institutes of Health. Mice were housed by sex in mixed genotype groups, with temperature maintained at $21 \pm 1{ }^{\circ} \mathrm{C}$ and humidity at $60 \pm 10 \%$. All experiments

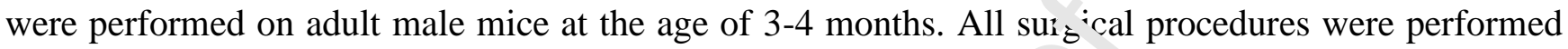
under anesthesia. Serum samples were obtained through rots bital blood sampling before euthanizing the animals. Once the animals were sacrificed, ${ }_{1}$ refrontal cortex and hippocampus were dissected out within 20s on an ice-cold surface and stored a ${ }^{\circ}{ }^{\circ} \mathrm{C}$ for further experiments.

\subsection{Serum extraction}

After retro-orbital sampling, blood was colı ted in microtubes and left for $1 \mathrm{~h}$ at room temperature and then centrifuged $\left(1500 \mathrm{rpm}, 10 \mathrm{~min} 4^{\circ} \mathrm{C}\right) \mathrm{f}$ r serum separation. Red blood cell hemolysis was evaluated by direct observation [53].

\subsection{HPLC analysis of amı. $\cdot$ acids content in brain and serum}

Brain samples were homogenized in $200 \mu \mathrm{L}$ of PBS and centrifuged at $20,000 \times g$ for $15 \mathrm{~min}$ at $4^{\circ} \mathrm{C}$. Subsequently, $10 \mu \mathrm{L}$ of $40 \mathrm{w} / \mathrm{v} \%$ trichloroacetic (TCA) and $150 \mu \mathrm{L}$ of water were added to $150 \mu \mathrm{L}$ of the supernatant, and the mixture was stored at $4^{\circ} \mathrm{C}$ for $10 \mathrm{~min}$. Precipitated proteins were then removed by centrifugation at $20,000 \times g$ for $15 \mathrm{~min}$ at $4^{\circ} \mathrm{C}$. To $150 \mu \mathrm{L}$ of the supernatant, $100 \mu \mathrm{L}$ of $200 \mathrm{mM}$ sodium borate buffer ( $\mathrm{pH} 8.0$ ), $20 \mu \mathrm{L}$ of $1 \mathrm{M} \mathrm{NaOH}$, and $130 \mu \mathrm{L}$ of water were added and mixed well. Then, $20 \mu \mathrm{L}$ of the mixture was mixed with $40 \mu \mathrm{L}$ of $50 \mathrm{mM}$ sodium borate buffer (pH 8.5) and $50 \mu \mathrm{L}$ of $10 \mathrm{mM}$ 4-fluoro-7-nitrobenzofurazan (NBD-F) in dry acetonitrile and incubated at $60^{\circ} \mathrm{C}$ for $5 \mathrm{~min}$ 
for fluorescence derivatization of free amino acids. After stopping the derivatization reaction by adding $890 \mu \mathrm{L}$ of $1 \%$ trifluoroacetic acid, $10 \mu \mathrm{L}$ of the sample solution was injected into the HPLC system as described below after filtration through a $0.45-\mu \mathrm{m}$ membrane filter. NBD-D- and L-Asp as well as NBD-D- and L-Ser were separated and fluorometrically detected by essentially following previously reported method [54]. In the case of NBD-D, L-Asp, columns of InertSustain C8 $(250 \times 4.6 \mathrm{~mm}$, i.d., 5 $\mu \mathrm{m}$, GL Sciences Inc., Tokyo, Japan $)$ and Sumichiral OA-3200 $(250 \times 4.6 \mathrm{~mm}$, i.d., $5 \mu \mathrm{m}$, Sumika Analytical Center, Osaka, Japan) were used as a reversed-phase ou vlsilyl silica gel column and a Pirkle-type chiral column, respectively. Column temperature war 3-or. The mobile phases used were $10 \mathrm{mM}$ sodium citrate $(\mathrm{pH} \mathrm{5.0)}$ : methanol $=88: 12(\mathrm{v} / \mathrm{v})(\mathrm{c} 8 \mathrm{~mL} / \mathrm{min})$ for the octylsilyl silica gel column and $8 \mathrm{mM}$ citrate in methanol:acetonitrile $=9.5,(0.8 \mathrm{~mL} / \mathrm{min})$ for the chiral column, respectively. For NBD-D, L-Ser, the columns were tl. ${ }^{\circ}$ sa ne as for NBD-D, L-Asp. The mobile phases used were $20 \mathrm{mM}$ sodium citrate $(\mathrm{pH} 6.0): \mathrm{m} \cdot$ the $.10 \mathrm{l}=88: 12(\mathrm{v} / \mathrm{v})(0.8 \mathrm{~mL} / \mathrm{min})$ for the octylsilyl silica gel column and $5 \mathrm{mM}$ citrate in methanoı $\cdot$ acetonitrile $=95: 5(0.8 \mathrm{~mL} / \mathrm{min})$ for the chiral column, respectively. Brain samples were alcn a n lyzed for L-Glu content, as previously described [55]. Prefrontal cortex (PFC) and hipp campus samples were homogenized in 1:10 (w/v) $0.2 \mathrm{M}$ TCA, sonicated ( 3 cycles, $10 \mathrm{~s}$ each) and centrifuged at $13,000 \mathrm{x} g$ for $20 \mathrm{~min}$. All the precipitated protein pellets from brain samples vere stored at $-80{ }^{\circ} \mathrm{C}$ for protein quantification. TCA supernatants were then neutralized with $0.2 \mathrm{M} \mathrm{NaOH}$ and subjected to precolumn derivatization with ophthaldialdehyde/N-acetyl-L-cysteine. Diastereoisomer derivatives were resolved on a Simmetry C8 5$\mu \mathrm{m}$ reversed-phase column (Waters, 4.6x250 mm). Identification and quantification were based on retention times and peak areas and compared with those associated with external standards. The detected L-Glu levels in the serum were expressed as $\mu \mathrm{M}$.

Serum samples were analyzed for D-Asp, L-Asp, D-Ser, L-Ser, and L-Glu, as previously reported [55]. Here, $100 \mu 1$ serum samples were mixed in a 1:10 dilution with HPLC-grade methanol (900 $\mu 1)$ and 
centrifuged at $13,000 \times \mathrm{g}$ for $10 \mathrm{~min}$. Supernatants were dried, suspended in $0.2 \mathrm{M}$ TCA, and then neutralized with $0.2 \mathrm{M} \mathrm{NaOH}$. Samples were then subjected to precolumn derivatization with ophthaldialdehyde (OPA)/N-acetyl-L-cysteine in 50\% methanol. Diastereoisomer derivatives were resolved on a Simmetry C8 5 - $\mu \mathrm{m}$ reversed-phase column (Waters, 4.6x250 mm) under isocratic conditions $(0.1 \mathrm{M}$ sodium acetate buffer, $\mathrm{pH} 6.2,1 \%$ tetrahydrofuran, and $1 \mathrm{ml} / \mathrm{min}$ flow rate). A washing step in $0.1 \mathrm{M}$ sodium acetate buffer, $3 \%$ tetrahydrofuran, and $47 \%$ acetonitrile was performed after every single run. Identification and quantification of D-Ser, I-Ser, D-Asp, L-Asp, and Lglutamate (L-Glu) were based on retention times and peak arear $7_{1}{ }^{-1}$.ompared with those associated with external standards. The identity of peaks was confirme.' by adding known amounts of external standards. The identity of the D-Asp peak was also evaluan a by selective degradation catalyzed by a recombinant human DDO (hDDO) [56, 57]; brief $v$, 1 DDO enzyme $(12.5 \mu \mathrm{g})$ was added to the samples, incubated at $30{ }^{\circ} \mathrm{C}$ for 3 hours, and subsequently derivatized. Amino acid levels were expressed as $\mu \mathrm{M}$, while the D-/total amino c -id ratio was expressed as percentage (\%).

\subsection{RNA extraction and qRT-PC:"}

Total RNA was extracted by י יsing the RNeasy mini kit (QIAGEN) according to the manufacturer's instructions. The integrity of the RNA was assessed by denaturing agarose gel electrophoresis (presence of sharp 28S, 18S, and 5S bands) and spectrophotometry (NanoDrop 2000, Thermo Scientific). Total RNA was purified to eliminate potentially contaminating genomic DNA using recombinant DNase (QIAGEN). A total of $1 \mu \mathrm{g}$ of total RNA of each sample was reverse-transcribed with Quanti Tect Reverse Transcription (QIAGEN) using oligo-dT and random primers mix according to the manufacturer's instructions. qRT-PCR amplifications were performed using LightCycler 480 SYBR Green I Master (Roche Diagnostic) in a LightCycler480 Real Time thermocycler (Roche). The following protocol was used: $10 \mathrm{~s}$ for initial denaturation at $95^{\circ} \mathrm{C}$ followed by 40 cycles consisting of 
$10 \mathrm{~s}$ at $94^{\circ} \mathrm{C}$ for denaturation, $10 \mathrm{~s}$ at $60^{\circ} \mathrm{C}$ for annealing, and $6 \mathrm{~s}$ for elongation at $72^{\circ} \mathrm{C}$. The following primers were used for mouse Ddo, Daao, $\mathrm{Sr}$ cDNA amplification: Ddo forward 5ACCACCAGTAATGTAGCGGC-3 and Ddo reverse 5-GGTACCGGGGTATCTGCAC-3; Daao forward 5-TTTTCTCCCGACACCTGGC-3 and Daao reverse 5-TGAACGGGGTGAATCGATCT-3; $\mathrm{Sr}$ forward 5-CCCTTGGTAGATGCACTGGT and $\mathrm{Sr}$ reverse 5-TCAGCAGCGTATACCTTCACAC3. $\beta$-actin and PP1A were used as housekeeping genes for PCR: $\beta$-actin forward 5CTAAGGCCAACCGTGAAAAG-3 and $\beta$-actin reverse 5-ACCAGA_GCATACAGGGACA-3, PP1A forward 5-GTGGTCTTTGGGAAGGTGAA-3 and PP1A reverse 5- זTACAGGACATTGCGAGCAG3.

\subsection{Statistical analysis}

Statistical analysis of HPLC detections we $\mathrm{p}$-rformed using Aspin-Welch's test, given the high

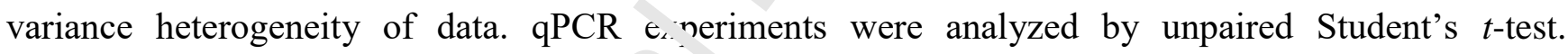
Correlation analyses were calculated 'siı o Pearson's correlation. All $p$ values less than 0.05 were considered statistically significant.

\section{Results}

\subsection{D-aspartate and L-aspartate content in the prefrontal cortex of ASD mouse models.}

HPLC measurements revealed a dramatic increase in D-Asp levels in PFC of BTBR mice, compared to the $\mathrm{C} 57 \mathrm{BL} / 6 \mathrm{~J}$ mice used as the control strain $(\mathrm{PFC}$ : $\mathrm{C} 57 \mathrm{BL} / 6 \mathrm{~J}=44.24 \pm 8.71 \mathrm{nmol} / \mathrm{g}$ tissue vs BTBR $=148.40 \pm 27.60 \mathrm{nmol} / \mathrm{g}$ tissue, $p=0.027$; Aspin-Welch's test; Figure 1a). In contrast to D-Asp, the amount of L-Asp was not significantly altered in of BTBR mice when compared to the C57BL/6J 
group $(\mathrm{C} 57 \mathrm{BL} / 6 \mathrm{~J}=3635 \pm 732 \mathrm{nmol} / \mathrm{g}$ tissue $\mathrm{vs} \mathrm{BTBR}=2642 \pm 550 \mathrm{nmol} / \mathrm{g}$ tissue, $p=0.323$; Aspin-

Welch's test; Figure 1b). Thus, consistent with the selective increase in D-Asp content, the D-Asp/total Asp $(\mathrm{D}+\mathrm{L})$ ratio was significantly higher in BTBR mice than in controls. $(\mathrm{C} 57 \mathrm{BL} / 6 \mathrm{~J}=1.21 \pm 0.05 \%$ vs $\mathrm{BTBR}=5.38 \pm 0.25 \%, p<0.0001$; Aspin-Welch’s test; Figure 1c).

HPLC analysis performed in Cntnap $2^{-/}$animals showed similar cortical levels of both D-Asp and LAsp, compared to the Cntnap $^{+/+}$mice, used as the control group (D-Asp: $p=0.523$; L-Asp: $p=0.670$; Aspin-Welch's test; Figure 1d,e). As a result, the D-Asp/total Asp ra ${ }^{i} \mathrm{o}$ did not significantly change between groups ( $p=0.083$; Figure 1f).

In Shank $3^{-/-}$mice, we did not observe any significant differen $~ *$ compared to the Shank $3^{+/+}$group in the amount of D-Asp and L-Asp, and D-Asp/total Asp ratio, (f Asp, $p=0.192$; L-Asp, $p=0.151$; D-/total Asp, $p=0.183$; Aspin-Welch's test; Figure 1g-i).

Like Shank $3^{--}$, also the $16 p 11.2^{+/-}$brains sho ${ }^{-e d}$ similar levels of D-Asp, L-Asp, and D-Asp/total Asp ratio compared to the control $16 p 11.2^{+/+} \mathrm{g}_{1}$ up (PFC: D-Asp, $p=0.756$; L-Asp, $p=0.838$; D-/total Asp ratio, $p=0.339$; Figure $1 \mathrm{j}-1)$.

Taken together, these HPLC data ighight a prominent increase in D-Asp levels within the PFC of BTBR mice. Conversely, no ${ }^{-} \mathrm{ro}_{-}$alterations in these amino acid levels were documented in the PFC of Cntnap $^{-/}$, Shank $3^{-/}$and ' $'$ p $1.2^{+/}$mutants when compared to their matched controls.

\subsection{D-aspartate and L-aspartate content in the hippocampus of ASD mouse models.}

Consistent with PFC data, HPLC analysis revealed a strong increase in D-Asp levels but not in L-Asp content in the hippocampus of BTBR mice, compared to the C57BL/6J mice (D-Asp: C57BL/6J $=$ $46.84 \pm 13.40 \mathrm{nmol} / \mathrm{g}$ tissue vs BTBR $=187.10 \pm 36.46 \mathrm{nmol} / \mathrm{g}$ tissue, $p=0.025 ; \mathrm{L}-\mathrm{Asp}:$ C57BL/6J $=$ $4616.00 \pm 1383.00 \mathrm{nmol} / \mathrm{g}$ tissue vs $\mathrm{BTBR}=4394.00 \pm 938.40 \mathrm{nmol} / \mathrm{g}$ tissue, $p=0.899$; Aspin-Welch's test; Figure 2a,b). In line with the selective increase in D-Asp content, the D-Asp/total Asp ratio was 
significantly higher in the hippocampus of BTBR mice compared to controls (C57BL/6J $=1.04 \pm 0.06$ $\%$ vs $\mathrm{BTBR}=4.15 \pm 0.15 \%, p<0.0001$; Aspin-Welch's test; Figure $2 \mathrm{c}$ ). Furthermore, we found a positive correlation between cortical and hippocampal D-Asp content in BTBR (Pearson's correlation, $r=0.942, p=0.058$; data not shown), but not in C57BL/6J animals (Pearson's correlation, $r=-0.182$, $p=0.818$; data not shown).

In contrast to the unaltered cortical levels of Asp enantiomers, HPLC data indicated a trend to decrease of $\sim 50 \%$ in the amount of both D-Asp and L-Asp in the hippocampu of Cntnap $2^{-/}$mice, compared to

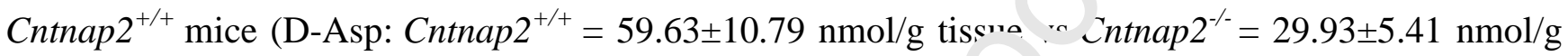
tissue, $p=0.064 ;$ L-Asp: Cntnap $^{+/+}=5859 \pm 1012 \mathrm{nmol} / \mathrm{g}$ issue vs Cntnap $2^{-/}=2844.00 \pm 320.60$ nmol/g tissue, $p=0.053$; Aspin-Welch's test; Figure 2d,e). ¿onsistent with a comparable reduction in both Asp enantiomers, we found a comparah ${ }^{-}$I -Asp/total Asp ratio between genotypes ( $p=0.842$; Aspin-Welch's test; Figure 2f).

In Shank $3^{--}$mice, we found unaltered level of D-Asp and L-Asp, and D-Asp/total Asp ratio compared to the Shank $^{+/+}$group (D-Asp, $p=0.8^{27}$; 1 - - ssp, $p=0.861$; D-Asp/total Asp ratio, $p=0.488$; Figure 2gi). Similarly, $16 p 11.2^{+/-}$mice hipp ampus showed similar levels of D-Asp, L-Asp, and D-Asp/total Asp ratio compared to the contr. $16 p 11.2^{+/+}$group (D-Asp, $p=0.585$; L-Asp, $p=0.874$; D-/total Asp ratio, $p=0.122$; Figure $2 \mathrm{j}-1$ ).

Overall, like PFC, we reported a prominent increase in D-Asp levels within the hippocampus of BTBR mice. In addition, we revealed significantly reduced D-Asp and L-Asp content in the hippocampus of Cntnap $2^{-/}$mice. In contrast, no significant changes in these amino acid levels were detected in Shank $^{-\%}$ and $16 p 11.2^{+/}$animals when compared to their matched controls.

\subsection{D-serine and L-serine levels in the prefrontal cortex and hippocampus of ASD mouse models}


Neurochemical experiments indicate that, despite there being no gross alterations in either D-Ser or LSer levels in PFC homogenates of BTBR animals (D-Ser: $p=0.871$; L-Ser: $p=0.875$; Aspin-Welch's test; Table 1), a mild reduction was found in the D-Ser/total Ser ratio when compared to the C57BL/6J control animals $(\mathrm{C} 57 \mathrm{BL} / 6 \mathrm{~J}=31.74 \pm 0.45 \%$ vs BTBR $=29.36 \pm 0.45 \%, p=0.009$; Aspin-Welch's test; Table 1). Conversely, in the hippocampus of BTBR, the amounts of D-Ser and L-Ser (D-Ser: $p=0.351$; L-Ser: $p=0.335$; Aspin-Welch's test; Table 1) as well as the D-Ser/total Ser ratio were comparable to those measured in C57BL/6J brains ( $p=0.393$; Aspin-Welch's test; Tư le 1). Besides no evident D-Ser alterations, we found a positive correlation between D-Ser $n n_{i} \mathrm{r}$-Asp levels within PFC and hippocampus of both BTBR (Pearson's correlation, PFC: $r=7.9 / 8, p=0.022$; hippocampus: $r=0.961$, $p=0.039$; data not shown) and C57BL/6J (Pearson's zorrelation, PFC: $r=0.965, p=0.035$; hippocampus: $r=0.998, p=0.002$; data not shown) mic .

In the PFC of Cntnap $2^{-}$, HPLC analysis dic no indicate any evident change in the amounts of D-Ser and L-Ser or in the D-Ser/total Ser ratio wh $\eta$ compared to those measured in the control group (D-Ser: $p=0.597$; L-Ser: $p=0.566$; D-Ser/total Se $\cdot,=0.631$; Aspin-Welch's test; Table 1). In contrast to the PFC, we revealed a decreasing tru $1 \mathrm{~d} 11$ the amounts of both D-Ser and L-Ser in the hippocampus of Cntnap $^{2 /}$ mutants compared tn $\llcorner$ r. .rols (D-Ser: $p=0.085$; L-Ser: $p=0.101$; Aspin-Welch's test; Table 1). Consistent with D-Ser a'd L-Ser levels, D-Ser/total Ser ratio was comparable between genotypes ( $p=0.447 ;$ Aspin-Welch's test; Table 1).

In Shank $3^{-/}$brains, cortical D-Ser levels tended to slightly increase compared to Shank $3^{+/+}$control mice ( $p=0.160$; Aspin-Welch's test; Figure 2m), while comparable L-Ser content and D-Ser/total Ser ratio were found between genotypes (L-Ser: $p=0.284$; D-Ser/total Ser ratio: $p=0.693$; Aspin-Welch's test; Table 1). In the hippocampus of Shank $3^{-/}$mice we detected no differences in D-Ser and L-Ser content and D-Ser/total Ser ratio as compared to Shank $3^{+/+}$animals (D-Ser: $p=0.937$; L-Ser: $p=0.930$; D-/total Ser ratio: $p=0.542$; Aspin-Welch's test; Table 1). 
Finally, we did not observe any gross alterations in D-Ser and L- Ser cerebral levels or in the DSer/total Ser ratio in either the PFC or hippocampus of $16 p 11.2^{+/-}$mice when compared to $16 p 11.2^{+/+}$control animals (PFC: D-Ser, $p=0.540$; L-Ser, $p=0.480$; D-/total Ser ratio, $p=0.744$; hippocampus: D-Ser, $p=0.534$; L-Ser, $p=0.540$; D-/total Ser ratio, $p=0.723$; Aspin-Welch's test; Table $1)$.

In conclusion, HPLC data indicate that D-Ser and L-Ser levels were only mildly altered within the PFC and hippocampus of BTBR, Cntnap $2^{-/}$, Shank $3^{-/}$and $16 p 11.2^{+/}$animat nodels of ASD.

\subsection{D-aspartate, L-aspartate and D-serine, L-serine con. ontrations in the serum of ASD mouse models}

Using HPLC, we also investigated levels of D-Asn, $\Gamma$-- 5 er, and their respective L-enantiomers in the serum of adult BTBR, Cntnap $2^{-/}$, Shank $3^{-/}$, a. $11, p 11.2^{+/-}$mice.

Consistent with the cerebral measuremen Asp/total Asp ratio in the serum of BTBR wice, compared to C57BL/6J animals (D-Asp: C57BL/6J = $0.56 \pm 0.29 \mu \mathrm{M}$ vs BTBR $=2.99 \pm 0 .{ }^{-4} \mu \mathrm{M}, p=0.012 ; \mathrm{D}-$ Asp/total Asp ratio: $\mathrm{C} 57 \mathrm{BL} / 6 \mathrm{~J}=3.12 \pm 0.96 \%$ vs BTBR $=10.23 \pm 2.06 \%, r$ ก.6? ; Aspin-Welch's test; Figure 3a, c). Notably, unlike the brain, we also observed a trend to inc ease in L-Asp amount in the serum of BTBR mice than in the controls $(\mathrm{C} 57 \mathrm{BL} / 6 \mathrm{~J}=14.65 \pm 4.03 \mu \mathrm{M}$ vs BTBR=26.76 $\pm 2.91 \mu \mathrm{M}, p=0.055$; Aspin-Welch’s test; Figure $3 \mathrm{~b})$.

We did not find any significant alterations in either D-Ser or L-Ser serum concentrations of BTBR mice (D-Ser, $p=0.224$; L-Ser, $p=0.384$; Aspin-Welch's test; Table 1). However, a mild increase in DSer/total Ser ratio was observed in BTBR mice when compared to C57BL/6J animals ( $p=0.053$; AspinWelch's test; Table 1).

Moreover, we detected comparable serum D-Asp and L-Asp levels and D-Asp/total Asp ratio in Cntnap $^{-/}$mutants as compared to Cntnap $2^{+/+}$controls (D-Asp, $p=0.216$; L-Asp, $p=0.679$; D-Asp/total 
Asp ratio, $p=0.153$; Figure 3d-f). Notably, although no gross changes were observed in the serum DSer and L-Ser levels in Cntnap $2^{-/}$mice (D-Ser, $p=0.842$; L-Ser, $p=0.287$; Aspin-Welch's test; Table 1), we detected significantly decreased D-Ser/total Ser ratio in these mutants as compared to their controls $\left(\right.$ Cntnap $^{+/+}=1.87 \pm 0.12 \%$ vs Cntnap $^{-/}=1.40 \pm 0.12 \%, p=0.036$; Aspin-Welch's test; Table $1)$.

Moreover, we found comparable serum D-Asp and L-Asp concentrations and D-Asp/total Asp ratio between Shank $^{-/}$and Shank ${ }^{+/+}$mice (D-Asp, $p=0.792$; L-Asp, $\left.p=0.\right\urcorner 74$; D-/total Asp ratio, $p=0.767$; Aspin-Welch's test; Figure 3g-i). Similarly, serum D-Ser and I S_- 'evels and D-Ser/total Ser ratio were also unaltered in these mutant mice (D-Ser, $p=0.636$; L- -1 r, $p=0.839$; D-/total Ser ratio, $p=0.573$; Aspin-Welch's test; Table 1).

We found no differences in the serum D-Asp, L-As? ${ }_{-}, \mathrm{I}-\mathrm{Ser}$, and L-Ser concentrations in $16 p 11.2^{+/}$ mice as compared to $16 p 11.2^{+/+}$controls ( $\mathrm{L} \cdot$ As,$~ p=0.351$; L-Asp, $p=0.537$; D-Ser, $p=0.187$; L-Ser, $p=0.581$; Figure 3j,k; Aspin-Welch's test; 氵able 1). Additionally, D-Asp/total Asp and D-Ser/total Ser ratios were not statistically different hatu ef n genotypes (D-Asp/total Asp ratio, $p=0.229$; D-Ser/total Ser ratio, $p=0.208$; Aspin-Welch's : st; rigure 31; Table 1).

Overall, HPLC experiments norl ${ }^{\text {rr }}$ ied in the serum confirmed the existence of dramatically increased D-Asp levels in BTBR aniı. ? Is, along with a significant reduction in D-Asp/total Asp ratio in Cntnap2 ${ }^{\prime}$ mutant mice. In contrast, no statistical differences in D-Asp, L-Asp and D-Ser, L-Ser levels were documented in Shank $3^{-/-}$and $16 p 11.2^{+/}$mutants when compared to their matched controls.

\subsection{L-glutamate content in the cortex, hippocampus, and serum of ASD mouse models}

We measured the content of L-Glu in the PFC, hippocampus, and serum of BTBR, Cntnap $2^{--}$, Shank $3^{--}$ and $16 p 11.2^{+/}$mice. Our HPLC analysis did not find any significant differences in L-Glu levels in the PFC of BTBR, Cntnap ${ }^{-/}$and $16 p 11.2^{+/}$mice compared to the respective control mice (BTBR, $p=0.645 ;$ Cntnap $^{-/}, p=0.915 ; 16 p 11.2^{+/}, p=0.462$; Aspin-Welch's test; Figure 4a,b,d). Similarly, we 
found no statistically significant changes in Shank $3^{-/}$mice, although a trend to decrease in L-Glu levels appeared, as compared to Shank $3^{+/+}$animals ( $p=0.060$; Aspin-Welch's test; Figure 4c).

In contrast to PFC, HPLC experiments showed a significant reduction in L-Glu concentration within the hippocampus of BTBR mice compared to C57BL/6J animals (C57BL/6J=6149 $\pm 427 \mathrm{nmol} / \mathrm{g}$ tissue vs $\mathrm{BTBR}=4841 \pm 182 \mathrm{nmol} / \mathrm{g}$ tissue, $p=0.027$; Aspin-Welch's test; Figure 4e). On the other hand, comparable L-Glu levels were found in the hippocampus of Cntnap $2^{-/}$, Shank $3^{-/}$, and $16 p 11.2^{+-}$ mutants when compared to their matched controls $\left(\right.$ Cntnap $^{-/}, p=0.131$ Shank $3^{-/}, p=0.496 ; 16 p 11.2^{+/}$, $p=0.168$; Aspin-Welch's test; Figure 4f,g,h).

Finally, we measured the serum L-Glu levels in all different 1 ice strains. Notably, we found increased L-Glu levels in BTBR mice compared to C57BL/6J animaı " $~=57 \mathrm{BL} / 6 \mathrm{~J}=37.08 \pm 11.00 \mu \mathrm{M}$ vs BTBR = 85.74 $\pm 4.94, p=0.014$; Aspin-Welch's test; Figure 4i’ C snversely, serum L-Glu concentrations were unaltered between Cntnap $^{-/}$, Shank $3^{-\%}$, and $5 p \quad 1.2^{+,-}$mutants and their matched controls (Cntnap $2^{-/}$, $p=0.708 ;$ Shank $3^{--}, p=0.326 ; 16 p 11.2^{+/}, p=\imath 452$; Aspin-Welch's test; Figure 4j,k,l).

Taken together, these data indicate a mbu st increase in L-Glu levels in the serum of BTBR, while no

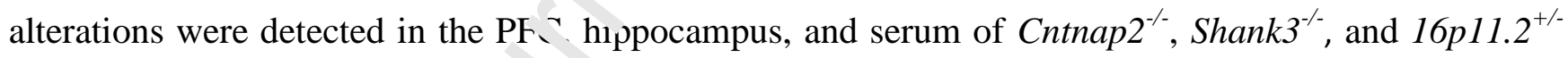
mice.

\subsection{Altered Ddo and Sr mRNA expression in the brain of BTBR mice}

Here, we analyzed the mRNA levels of the genes involved in the regulation of D-Asp and D-Ser synthesis and degradation. To this aim, we conducted qRT-PCR to determine the transcript levels of Ddo, Daao, and $S r$ in both the PFC and hippocampus of BTBR, Cntnap $2^{-\%}$, Shank $3^{-\%}$, and $16 p 11.2^{+/}$ and matched control mice.

In line with the dramatic increase in D-Asp content, we found a robust reduction in Ddo transcript levels in both the PFC and hippocampus of BTBR mice compared to C57BL/6J animals (PFC, 
$p<0.0001$; hippocampus, $p<0.0001$; Figure 5 a, d). Conversely, no significant alterations in Ddo gene expression were observed in either the PFC or hippocampus of Cntnap ${ }^{-/}$, Shank $3^{-/}$, and $16 p 11.2^{+/-}$ mice compared with their respective controls (PFC: Cntnap $^{-/}, p=0.2602 ;$ Shank $3^{-/}, p=0.082$; $16 p 11.2^{+/}, p=0.524$; hippocampus: Cntnap $2^{-/}, p=0.1771 ;$ Shank3 $^{-/}, p=0.663 ; 16 p 11.2^{+/}, p=0.884$; unpaired Student's $t$-test; Figure 5g,j,m,p,s,v).

The analysis of Daao mRNA levels revealed that this transcript was almost undetectable in all the brain samples analyzed, even after 40 PCR cycles (Figure 5b,e,h,k,n,q,t,w).

On the other hand, qPCR analysis of $S r$ gene expression revealed ${ }^{\prime} \eta_{\omega^{\prime}}{ }^{1+}$-red mRNA levels in the PFC of BTBR mice, compared to C57BL/6J animals ( $p=0.149$; unpa.. ${ }^{2}$ Student's $t$-test; Figure 5c); however, a statistically significant increase was detected in the hippo. - apus of these animals ( $p=0.005$; unpaired Student's $t$-test; Figure 5f). Conversely, in Shank $3^{-1} 1$ ce we observed reduced $S r$ mRNA levels in the PFC but not in the hippocampus (PFC, $p=1.0^{\circ} 3$; hippocampus, $p=0.406$; unpaired Student's $t$-test; Figure 5o, r). Finally, we found unalterec $S r$ transcripts within the PFC and hippocampus of both Cntnap $^{-{ }^{-}}$and $16 p 11.2^{+/}$mice comp ${ }^{\text {red }}$ tr matched controls (PFC: Cntnap2 $2^{-/}, p=0.158 ; 16 p 11.2^{+/}$, $p=0.831$; hippocampus; Cntnap $2^{-/}, p=0.401 ; 16 p 11.2^{+/}, p=0.681$; unpaired Student's $t$-test; Figure $5 i, 1, u, x)$.

Overall, these qPCR experı nents highlight a dramatic reduction in Ddo mRNA expression within the PFC and hippocampus of BTBR mice, along with a significant increase in $S r$ transcripts in the hippocampus of the same animals. On the other hand, no gross changes in genes regulating D-amino acids metabolism were found in Cntnap $2^{-/}$, Shank $3^{--}$, or $16 \mathrm{p} 11.2^{+/-}$animals when compared to matched controls.

\section{Discussion}


It is well known that dysregulated glutamatergic signaling is involved in the etiology of ASD [8-14]. Several studies in mouse models of ASD have shown abnormalities in synaptic plasticity due to dysfunctions in the NMDAR and AMPAR systems [58]. Pharmacological evidence in mouse models with deletions in synaptic genes Fmr1, Mecp2, and Shank2, and in the inbred BTBR strain also supports the hypothesis of altered glutamatergic transmission since treatment with glutamatergic drugs, including memantine, has demonstrated favorable outcomes [59-61]. In parallel to preclinical research, studies in ASD patients reported significantly increased serum and pissma glutamate concentrations, compared to healthy subjects [62-64]. Accordingly, a post-mnr w... study has shown augmented glutamate and glutamine content in the anterior cingulate corn $x$ or a small cohort of seven individuals with autism [65].

Here, we explored the putative implication of an alt "ed metabolism of the NMDAR modulators, DAsp and D-Ser, in the physiopathology of $A_{2}$ iD We evaluated the cerebral content of these D-amino acids in different genetic mouse models or. $\mathrm{SD}$, such as knockout mice for Cntnap2 (Cntnap $\left.2^{--} ;[4]\right)$, Shank3B (Shank3 $3^{-/}$; [6]), and heteroz'rou s nice with 16p11.2 deletion $\left(16 p 11.2^{+/-}\right.$; [7]). Noteworthy, all these animal models show core. SD-like brain and behavioral deficits at the age of our biochemical characterization [50-52]. In adai ir n to these syndromic models, we also analyzed BTBR mice, an idiopathic animal model or 4دD [49, 66-68]. Although genetic and molecular abnormalities causing behavioral deficits in BTBR mice remain unclear [49, 69], this inbred mouse strain incorporates behavioral phenotypes relevant to all diagnostic symptoms of ASD, including reduced social interactions in juveniles and adults, repetitive self-grooming, and an unusual pattern of ultrasonic vocalizations resembling the atypical vocalizations that some autistic children produce [70, 71]. Moreover, BTBR mice show a severely reduced hippocampal commissure and absent corpus callosum [72], along with dysfunctional dopamine D2 receptor striatal neurotransmission and blunted 
mesolimbic activity [73]. Of note, corpus callosum abnormalities have been also reported in autistic individuals $[74,75]$.

Here, we document a severe, dysfunctional D-Asp metabolism in BTBR brain (Table 2). Indeed, we found a very prominent increase in D-Asp content along with a severe reduction in Ddo gene expression in both the PFC and hippocampus of BTBR animals, compared to the same brain regions of C57BL/6J mice (Table 2). In agreement with this observation, previous transcriptome profiling identified Ddo among the 580 downregulated genes in the hippocamp s of BTBR adult mice [76]. We also detected increased $S r$ transcript levels in BTBR hippocamnי's. Talis gene, encoding the enzyme responsible for D-Ser biosynthesis [77], has been suggesı t to take part also in cerebral D-Asp production [34-36]. Nevertheless, since 1) D-Ser levels ar anchanged in the hippocampus of BTBR mice compared to controls, and 2) SR enzyme disnl، s : much higher activity on the synthesis of DSer compared to D-Asp [35], it seems un' kel $f$ that the observed increase in $S r$ gene expression contributes to D-Asp elevation in this bran. region of BTBR mice. Future studies will help to clarify whether $S r$ mRNA changes turn intr a te ed SR protein levels and enzymatic activity in BTBR hippocampus. In line with these fi. lings, we also report higher D-Asp concentrations in the serum of the BTBR strain than in the rnni. ${ }^{1}$ mice. In this regard, it will be mandatory to evaluate the potential relevance of D-Asp as a n ver biomarker for diagnostic measurements in idiopathic forms of ASD. Consistent with the agonism activity of D-Asp on NMDARs [27], we hypothesize that the altered DAsp metabolism found in BTBR brain could influence NMDAR-dependent functions in this widely used idiopathic animal model of ASD [49, 66-68]. Yet, D-Asp is an agonist of mGluR5 [28] and, therefore, any increase in its levels should boost these receptors and, consequently, NMDARs function. Previous studies have investigated the influence of increased endogenous D-Asp content in knockout mice for Ddo gene, an animal model backcrossed to C57BL/6J strain [78]. In line with well-established detrimental effects associated to overstimulation of NMDARs [79], it has been reported that a 
persistent increase in D-Asp levels results in the precocious decay of basal glutamatergic transmission, synaptic plasticity, and hippocampal reference memory in mutants [80-82]. Such dysfunctions are mirrored by the loss of excitatory glutamatergic synapses and reduction in synaptic GluN1 and GluN2B subunits [82]. In addition, severe age-dependent neuroinflammation and cell death occur within PFC and hippocampus of Ddo knockout animals [81]. On the other hand, increased D-Asp levels in youngadult Ddo knockout mice have been associated with improved functional and structural NMDARdependent synaptic plasticity. Based on this set of evidence, future stu'ies are mandatory to clarify the impact of D-Asp metabolism in the genetic background of RTb? mice. Nevertheless, it remains unclear whether the broad alterations in D-Asp metaboil. $m$ tound in BTBR mice represent a developmentally relevant contribution or reflect chang, occurring only in adulthood. Further experiments on juvenile BTBR mice are needed to $i_{\mathrm{L}^{\mathrm{V}}}$ sst gate this point. It is important also to remark that D-Asp is abundant during brain develc ${ }_{1}$ me.tt [29-31]. In this regard, the recent generation of a mouse model characterized by precocious ı mbryonic D-Asp depletion [31] may help in clarifying the potential involvement of this D-amino ncic i i a neurodevelopmental disorder like ASD.

Interestingly, we also found high $\cdot$ coucentrations of the enantiomer L-Asp in the serum of BTBR mice, thus suggesting an overall ${ }^{a r}$ pheral dysregulation of Asp metabolism. In addition to D-Asp, we also found a slight reducion in L-Glu levels in the hippocampus of BTBR mice, along with a substantial increase of this amino acid in the serum. These opposite L-Glu changes might suggest that the observed cerebral and peripheral dysfunctions have separate metabolic origins in the BTBR strain, since this amino acid cannot pass the blood-brain barrier [83]. Remarkably, our observation showing higher L-Glu levels in BTBR serum is consistent with a previous study in humans reporting significantly higher L-Glu serum levels in patients with idiopathic autism [62].

It must be pointed out here that the changes observed in BTBR might somehow be affected by the choice of the comparison strain, namely, C57BL/6J mice. However, such a strain is commonly used for 
comparison with BTBR in molecular and behavioral studies [67]. Another limitation is based on the fact that our HPLC analyses were performed on total homogenates. Consequently, we measured the total amount of amino acids without distinguishing between the extracellular fraction and intracellular (neuronal vs glial) metabolic pool.

In support of a selective metabolic D-Asp alteration within BTBR brain, all the other three syndromic mouse models of ASD examined did not exhibit gross perturbations in amino acids metabolism in either brain or serum (Table 2). We only found reduced hippocampal « ntent of both D-Asp and L-Asp but unaltered D-Asp/total Asp ratio and Ddo gene expression $i_{1} C_{n t n a p} 2^{-/}$mice. These findings suggest that D-Asp modification observed in Cntnap2 ${ }^{-/}$anim. 's could be an indirect consequence of a regional alteration in L-Asp metabolism. Overall, the resulı collected in the genetic mouse models of ASD suggest that the single mutations examined, ass - ia ed to syndromic forms of ASD, are not able to trigger a metabolic D-Asp imbalance in ad Ith'od. Despite D-Asp metabolism selectively changes in BTBR mice, this idiopathic ASD model a as not exhibit specific behavioral phenotypes compared to syndromic ASD mouse models [49-5? 811 Therefore, we cannot predict if specific alterations found in D-Asp metabolism are selective, assuciated with peculiar BTBR-related ASD phenotypes.

Overall, our findings indicate that netabolic D-Asp dysfunction could represent one of the complex biological components inv lved in idiopathic forms of ASD. On the other hand, the absence of significant D-Ser changes in all ASD animal models analyzed here does not match with previous biochemical and pharmacological studies in preclinical models and ASD children. Indeed, significant alteration in the serum and urine concentrations of D-Ser and L-Ser has been reported in ASD patients [63, 85-88]. Furthermore, a rescue of behavioural alterations in preclinical models and ASD patients has been demonstrated by improving the occupancy of the glycine B site of NMDARs with Dcycloserine and sarcosine supplementation [89-91]. It is important to remark that our neurochemical analyses were conducted in adult animals while ASD mainly involves neurodevelopmental 
dysfunctions that result in clear phenotypes at juvenile stages of life. Remarkably, such juvenile phenotypes differ from those at adulthood at the molecular level [89]. Studies have now established that ASD is associated, at least in animal models, to early hyperfunction of NMDAR before weaning while switching to hypofunction after this period [89]. Based on this consideration, it is conceivable that the lack of any detectable cerebral D-Ser alterations in adult ASD animal models does not imply the absence of any alterations earlier on. Indeed, clinical studies have established that Ser levels are decreased in subjects with ASD $[63,85,87,88]$ and that inhibitors of 2 AAO such as sodium benzoate could be effective for treating ASD in children, as reported in a ni. investigations are needed to examine the same biochemical mı asurements both at prenatal and juvenile stages of life.

Another issue that deserves to be deeply investigated $i_{1} \mathrm{f}$ tture studies is the potential impact of D-Asp and D-Ser food integration in ASD. In this $r \cdot \mathrm{ga}^{r} \mathrm{~d}$, considering the relevance of food intake on amino acid metabolism, next experiments are mandatory to evaluate whether specific Asp/Ser-deprived or enriched food regime might affect hrain and systemic metabolism of ASD mouse models and influence, in turn, their ASD-relate, phenotypes.

\section{Conclusions}

In this work, we report that, on top of alterations in L-Glu levels, an idiopathic animal model of ASD, such as BTBR, exhibits robust metabolic perturbation in the NMDAR and mGluR5 agonist D-Asp. This evidence supports on one hand the involvement of an abnormal glutamatergic neurotransmission in the pathophysiology of idiopathic ASD, on the other hand highlight the D-Asp metabolism contribution in the dysfunctional glutamatergic neurotransmission observed in idiopathic ASD. 
Acknowledgments: A.U. was supported by a grant from MIUR (Ministero dell'Istruzione, dell'Università e della Ricerca, Progetto PRIN 2017-Project nr 2017M42834). A.G. is supported by the European Research Council (ERC, DISCONN to A.G., Grant Agreement 802371), the Simons Foundation (SFARI 400101), the Brain and Behavior Foundatio. (NARSAD, \#25861), the NIH (1R21MH116473-01A1), Telethon Foundation (GGP19177) ana the University of Padua interdepartmental project "Proactive". 


\section{References}

[1] C. Lord, T.S. Brugha, T. Charman, J. Cusack, G. Dumas, T. Frazier, E.J.H. Jones, R.M. Jones, A.

Pickles, M.W. State, J.L. Taylor, J. Veenstra-VanderWeele, Autism spectrum disorder, Nat Rev Dis Primers, 6 (2020) 5.

[2] F.R. Volkmar, D. Pauls, Autism, Lancet, 362 (2003) 1133-1141.

[3] L.M. Iakoucheva, A.R. Muotri, J. Sebat, Getting to the Cores of Autism, Cell, 178 (2019) 12871298.

[4] A. Liska, A. Bertero, R. Gomolka, M. Sabbioni, A. Ga' ous ra, N. Barsotti, S. Panzeri, M.L. Scattoni, M. Pasqualetti, A. Gozzi, Homozygous Loss of ^ u ism-Risk Gene CNTNAP2 Results in Reduced Local and Long-Range Prefrontal Functional Conwstivity, Cereb Cortex, 28 (2018) 11411153.

[5] J.D. Murdoch, M.W. State, Recent develop. ents in the genetics of autism spectrum disorders, Curr Opin Genet Dev, 23 (2013) 310-315.

[6] M. Pagani, A. Bertero, A. Lisl.a, 4. Galbusera, M. Sabbioni, N. Barsotti, N. Colenbier, D. Marinazzo, M.L. Scattoni, M. Pa qu. letti, A. Gozzi, Deletion of Autism Risk Gene Shank3 Disrupts Prefrontal Connectivity, J N urc `c1, 39 (2019) 5299-5310.

[7] A. Bertero, A. Liska, 11. Pagani, R. Parolisi, M.E. Masferrer, M. Gritti, M. Pedrazzoli, A. Galbusera, A. Sarica, A. Cerasa, M. Buffelli, R. Tonini, A. Buffo, C. Gross, M. Pasqualetti, A. Gozzi, Autism-associated 16p11.2 microdeletion impairs prefrontal functional connectivity in mouse and human, Brain, 141 (2018) 2055-2065.

[8] J. Horder, M.M. Petrinovic, M.A. Mendez, A. Bruns, T. Takumi, W. Spooren, G.J. Barker, B. Kunnecke, D.G. Murphy, Glutamate and GABA in autism spectrum disorder-a translational magnetic resonance spectroscopy study in man and rodent models, Transl Psychiatry, 8 (2018) 106. 
[9] D. Khalifa, O. Shahin, D. Salem, O. Raafat, Serum glutamate was elevated in children aged 3-10 years with autism spectrum disorders when they were compared with controls, Acta Paediatr, 108 (2019) 295-299.

[10] H.F. Zheng, W.Q. Wang, X.M. Li, G. Rauw, G.B. Baker, Body fluid levels of neuroactive amino acids in autism spectrum disorders: a review of the literature, Amino Acids, 49 (2017) 57-65.

[11] E.J. Lee, S.Y. Choi, E. Kim, NMDA receptor dysfunction in autism spectrum disorders, Curr Opin Pharmacol, 20 (2015) 8-13.

[12] E. Moretto, L. Murru, G. Martano, J. Sassone, M. Prc $\mathcal{G}_{n}^{f_{n}}$.o, Glutamatergic synapses in neurodevelopmental disorders, Prog Neuropsychopharmacol i:ol rsychiatry, 84 (2018) 328-342.

[13] G. Uzunova, E. Hollander, J. Shepherd, The role of 1 - vtropic glutamate receptors in childhood neurodevelopmental disorders: autism spectrum di orders and fragile $\mathrm{x}$ syndrome, Curr Neuropharmacol, 12 (2014) 71-98.

[14] R.F. Tzang, C.H. Chang, Y.C. Chang, H.Y. Lane, Autism Associated With Anti-NMDAR Encephalitis: Glutamate-Related Therany, Fr snt Psychiatry, 10 (2019) 440.

[15] S.W. Hulbert, Y.H. Jiang, N' nnogenic mouse models of autism spectrum disorders: Common mechanisms and missing linke N oscience, 321 (2016) 3-23.

[16] T. Rinaldi, K. Kulan ara, K. Antoniello, H. Markram, Elevated NMDA receptor levels and enhanced postsynaptic long-term potentiation induced by prenatal exposure to valproic acid, Proc Natl Acad Sci U S A, 104 (2007) 13501-13506.

[17] M.V. Mehta, M.J. Gandal, S.J. Siegel, mGluR5-antagonist mediated reversal of elevated stereotyped, repetitive behaviors in the VPA model of autism, PLoS One, 6 (2011) e26077.

[18] J.T. Coyle, Glutamate and schizophrenia: beyond the dopamine hypothesis, Cell Mol Neurobiol, 26 (2006) 365-384. 
[19] S.L. Grant, Y. Shulman, P. Tibbo, D.R. Hampson, G.B. Baker, Determination of d-serine and related neuroactive amino acids in human plasma by high-performance liquid chromatography with fluorimetric detection, J Chromatogr B Analyt Technol Biomed Life Sci, 844 (2006) 278-282.

[20] V. Labrie, T. Lipina, J.C. Roder, Mice with reduced NMDA receptor glycine affinity model some of the negative and cognitive symptoms of schizophrenia, Psychopharmacology (Berl), 200 (2008) 217-230.

[21] K.S. Lam, M.G. Aman, L.E. Arnold, Neurochemical correlates o. vitistic disorder: a review of the literature, Res Dev Disabil, 27 (2006) 254-289.

[22] D. Ongur, J.E. Jensen, A.P. Prescot, C. Stork, M. Lund, B.M. Cohen, P.F. Renshaw, Abnormal glutamatergic neurotransmission and neuronal-glial intera ‘ uns in acute mania, Biol Psychiatry, 64 (2008) 718-726.

[23] C. Yuksel, D. Ongur, Magnetic resonan e sr ectroscopy studies of glutamate-related abnormalities in mood disorders, Biol Psychiatry, 68 (201?) 785-794.

[24] A.R. Durrant, U. Heresco-Levy J- Jerine in Neuropsychiatric Disorders: New Advances, Advances in Psychiatry, 2014 (201 ) 857735.

[25] M. Martineau, G. Baux J.? Mothet, D-serine signalling in the brain: friend and foe, Trends Neurosci, 29 (2006) 481-4乡:

[26] H. Wolosker, D.T. Balu, J.T. Coyle, The Rise and Fall of the d-Serine-Mediated Gliotransmission Hypothesis, Trends Neurosci, 39 (2016) 712-721.

[27] F. Errico, T. Nuzzo, M. Carella, A. Bertolino, A. Usiello, The Emerging Role of Altered dAspartate Metabolism in Schizophrenia: New Insights From Preclinical Models and Human Studies, Front Psychiatry, 9 (2018) 559. 
[28] G. Molinaro, S. Pietracupa, L. Di Menna, L. Pescatori, A. Usiello, G. Battaglia, F. Nicoletti, V. Bruno, D-aspartate activates mGlu receptors coupled to polyphosphoinositide hydrolysis in neonate rat brain slices, Neurosci Lett, 478 (2010) 128-130.

[29] A. Hashimoto, S. Kumashiro, T. Nishikawa, T. Oka, K. Takahashi, T. Mito, S. Takashima, N. Doi, Y. Mizutani, T. Yamazaki, et al., Embryonic development and postnatal changes in free D-aspartate and D-serine in the human prefrontal cortex, J Neurochem, 61 (1993) 348-351.

[30] D.S. Dunlop, A. Neidle, D. McHale, D.M. Dunlop, A. Lajtha, Thu nresence of free D-aspartic acid in rodents and man, Biochem Biophys Res Commun, 141 (1986) 27-??

[31] A. De Rosa, F. Mastrostefano, A. Di Maio, T. Nuzzo, Y. saitoh, M. Katane, A.M. Isidori, V. Caputo, P. Marotta, G. Falco, M.E. De Stefano, H. Homma, '. Usiello, F. Errico, Prenatal expression

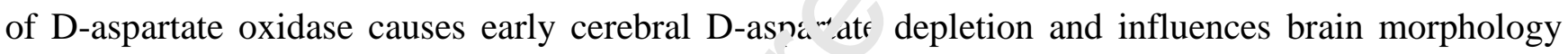
and cognitive functions at adulthood, Amino tcir.s, 52 (2020) 597-617.

[32] H. Wolosker, D-serine regulation of N ' TDA receptor activity, Sci STKE, 2006 (2006) pe41.

[33] L. Pollegioni, S. Sacchi, Metaboli`m if he neuromodulator D-serine, Cell Mol Life Sci, 67 (2010) 2387-2404.

[34] M. Horio, T. Ishima, $Y F_{h}{ }_{j}{ }^{i t}$, , R. Inoue, H. Mori, K. Hashimoto, Decreased levels of free Daspartic acid in the forebraı or serine racemase (Srr) knock-out mice, Neurochem Int, 62 (2013) 843847.

[35] T. Ito, M. Hayashida, S. Kobayashi, N. Muto, A. Hayashi, T. Yoshimura, H. Mori, Serine racemase is involved in d-aspartate biosynthesis, J Biochem, 160 (2016) 345-353.

[36] A. Tanaka-Hayashi, S. Hayashi, R. Inoue, T. Ito, K. Konno, T. Yoshida, M. Watanabe, T. Yoshimura, H. Mori, Is D-aspartate produced by glutamic-oxaloacetic transaminase-1 like 1 (Got111): a putative aspartate racemase?, Amino Acids, 47 (2015) 79-86. 
[37] S. Sacchi, L. Caldinelli, P. Cappelletti, L. Pollegioni, G. Molla, Structure-function relationships in human D-amino acid oxidase, Amino Acids, 43 (2012) 1833-1850.

[38] G. Murtas, S. Sacchi, M. Valentino, L. Pollegioni, Biochemical Properties of Human D-Amino Acid Oxidase, Front Mol Biosci, 4 (2017) 88.

[39] M. Katane, H. Homma, D-aspartate oxidase: the sole catabolic enzyme acting on free D-aspartate in mammals, Chem Biodivers, 7 (2010) 1435-1449.

[40] E.A. Nunes, E.M. MacKenzie, D. Rossolatos, J. Perez-Parada, G.2 Baker, S.M. Dursun, D-serine and schizophrenia: an update, Expert Rev Neurother, 12 (2012) 8n1-21?

[41] D.T. Balu, J.T. Coyle, The NMDA receptor 'glycine mu 'ulatory site' in schizophrenia: D-serine, glycine, and beyond, Curr Opin Pharmacol, 20 (2015) 109-1 15.

[42] Y. Ozeki, M. Sekine, K. Fujii, T. Watanabe, H. 'Jk ıyasu, Y. Takano, T. Shinozaki, A. Aoki, K. Akiyama, H. Homma, K. Shimoda, Phosp' ose ine phosphatase activity is elevated and correlates negatively with plasma d-serine concentration in patients with schizophrenia, Psychiatry Res, 237 (2016) 344-350.

[43] T. Nuzzo, S. Sacchi, F. Erric '. S. Keller, O. Palumbo, E. Florio, D. Punzo, F. Napolitano, M. Copetti, M. Carella, L. Chiarinti. A. Bertolino, L. Pollegioni, A. Usiello, Decreased free d-aspartate levels are linked to enhan ${ }^{-a}$ d-aspartate oxidase activity in the dorsolateral prefrontal cortex of schizophrenia patients, NPJ Schizophr, 3 (2017) 16.

[44] J. Yamada, A. Okabe, H. Toyoda, W. Kilb, H.J. Luhmann, A. Fukuda, Cl- uptake promoting depolarizing GABA actions in immature rat neocortical neurones is mediated by NKCC1, J Physiol, 557 (2004) 829-841.

[45] L.J. Young, C.E. Barrett, Neuroscience. Can oxytocin treat autism?, Science, 347 (2015) 825-826.

[46] K. Hashimoto, T. Yoshida, M. Ishikawa, Y. Fujita, T. Niitsu, M. Nakazato, H. Watanabe, T. Sasaki, A. Shiina, T. Hashimoto, N. Kanahara, T. Hasegawa, M. Enohara, A. Kimura, M. Iyo, 
Increased serum levels of serine enantiomers in patients with depression, Acta Neuropsychiatr, 28 (2016) 173-178.

[47] L. Deutschenbaur, J. Beck, A. Kiyhankhadiv, M. Muhlhauser, S. Borgwardt, M. Walter, G. Hasler, D. Sollberger, U.E. Lang, Role of calcium, glutamate and NMDA in major depression and therapeutic application, Prog Neuropsychopharmacol Biol Psychiatry, 64 (2016) 325-333.

[48] K. Hashimoto, D. Bruno, J. Nierenberg, C.R. Marmar, H. Zetterberg, K. Blennow, N. Pomara, Abnormality in glutamine-glutamate cycle in the cerebrospinal fliw ${ }^{-1}$ of cognitively intact elderly individuals with major depressive disorder: a 3-year follow-up stridv, T ansl Psychiatry, 6 (2016) e744. [49] K.Z. Meyza, D.C. Blanchard, The BTBR mouse mode of 1diopathic autism - Current view on mechanisms, Neuroscience \& Biobehavioral Reviews, 76 ( $2 ? 1 /$ ) 99-110.

[50] O. Penagarikano, B.-á. Abrahams, E.-á. Herm `, X.-á. Winden, A. Gdalyahu, H. Dong, L.á. Sonnenblick, R. Gruver, J. Almajano, A. ‘ras,ın, Y. Golshani, J.-á. Trachtenberg, E. Peles, D.-á. Geschwind, Absence of CNTNAP2 Leads +o Epilepsy, Neuronal Migration Abnormalities, and Core Autism-Related Deficits, Cell, 147 (2011) ?25-246.

[51] J. Peca, C. Feliciano, J.T. Tinধ, W. Wang, M.F. Wells, T.N. Venkatraman, C.D. Lascola, Z. Fu, G. Feng, Shank3 mutant mice dicnlà.' 'utistic-like behaviours and striatal dysfunction, Nature, 472 (2011) 437-442.

[52] G. Horev, J. Ellegood, J.P. Lerch, Y.E.E. Son, L. Muthuswamy, H. Vogel, A.M. Krieger, A. Buja, R.M. Henkelman, M. Wigler, A.A. Mills, Dosage-dependent phenotypes in models of 16p11.2 lesions found in autism, Proceedings of the National Academy of Sciences of the United States of America, 108 (2011) 17076-17081.

[53] I. Fernandez, A. Pena, N. Del Teso, V. Perez, J. Rodriguez-Cuesta, Clinical biochemistry parameters in C57BL/6J mice after blood collection from the submandibular vein and retroorbital plexus, J Am Assoc Lab Anim Sci, 49 (2010) 202-206. 
[54] Z. Long, N. Nimura, M. Adachi, M. Sekine, T. Hanai, H. Kubo, H. Homma, Determination of Dand L-aspartate in cell culturing medium, within cells of MPT1 cell line and in rat blood by a columnswitching high-performance liquid chromatogrpahic method, J Chromatogr B Biomed Sci Appl, 761 (2001) 99-106.

[55] T. Nuzzo, D. Punzo, P. Devoto, E. Rosini, S. Paciotti, S. Sacchi, Q. Li, M.L. Thiolat, C. Vega, M. Carella, M. Carta, F. Gardoni, P. Calabresi, L. Pollegioni, E. Bezard, L. Parnetti, F. Errico, A. Usiello, The levels of the NMDA receptor co-agonist D-serine are reduced it the substantia nigra of MPTPlesioned macaques and in the cerebrospinal fluid of Parkinson'c ain ase patients, Sci Rep, 9 (2019) 8898.

[56] M. Katane, H. Kuwabara, K. Nakayama, Y. Saitoh, T. ^ilyamoto, M. Sekine, H. Homma, Rat daspartate oxidase is more similar to the human enzyn o th in the mouse enzyme, Biochim Biophys Acta Proteins Proteom, 1866 (2018) 806-812.

[57] M. Katane, R. Kanazawa, R. Kobaya hi, M. Oishi, K. Nakayama, Y. Saitoh, T. Miyamoto, M. Sekine, H. Homma, Structure-function re at onships in human d-aspartate oxidase: characterisation of variants corresponding to known ingle nucleotide polymorphisms, Biochim Biophys Acta Proteins Proteom, 1865 (2017) 1129-114し.

[58] J.L. Silverman, J.N. ¿`awley, The promising trajectory of autism therapeutics discovery, Drug Discov Today, 19 (2014) 838-844.

[59] H. Wei, C. Dobkin, A.M. Sheikh, M. Malik, W.T. Brown, X. Li, The therapeutic effect of memantine through the stimulation of synapse formation and dendritic spine maturation in autism and fragile X syndrome, PLoS One, 7 (2012) e36981.

[60] D.C. Rojas, The role of glutamate and its receptors in autism and the use of glutamate receptor antagonists in treatment, J Neural Transm (Vienna), 121 (2014) 891-905. 
[61] L.K. Fung, A.Y. Hardan, Developing Medications Targeting Glutamatergic Dysfunction in Autism: Progress to Date, CNS Drugs, 29 (2015) 453-463.

[62] A. Shinohe, K. Hashimoto, K. Nakamura, M. Tsujii, Y. Iwata, K.J. Tsuchiya, Y. Sekine, S. Suda, K. Suzuki, G. Sugihara, H. Matsuzaki, Y. Minabe, T. Sugiyama, M. Kawai, M. Iyo, N. Takei, N. Mori, Increased serum levels of glutamate in adult patients with autism, Prog Neuropsychopharmacol Biol Psychiatry, 30 (2006) 1472-1477.

[63] R. Tirouvanziam, T.V. Obukhanych, J. Laval, P.A. Aronov, ' Libove, A.G. Banerjee, K.J. Parker, R. O'Hara, L.A. Herzenberg, L.A. Herzenberg, A.Y. Harda. Jistinct plasma profile of polar neutral amino acids, leucine, and glutamate in children with A tism Spectrum Disorders, J Autism Dev Disord, 42 (2012) 827-836.

[64] C. Shimmura, S. Suda, K.J. Tsuchiya, K. Ha ${ }^{-1}$ 1n oto, K. Ohno, H. Matsuzaki, K. Iwata, K. Matsumoto, T. Wakuda, Y. Kameno, K. Suzı «i, 'A. Tsujii, K. Nakamura, N. Takei, N. Mori, Alteration of plasma glutamate and glutamine levels in children with high-functioning autism, PLoS One, 6 (2011) e25340.

[65] C. Shimmura, K. Suzuki, Y. I 'ata, K.J. Tsuchiya, K. Ohno, H. Matsuzaki, K. Iwata, Y. Kameno, T. Takahashi, T. Wakuda, K. Nai ariura, K. Hashimoto, N. Mori, Enzymes in the glutamate-glutamine cycle in the anterior cingu' te cortex in postmortem brain of subjects with autism, Mol Autism, 4 (2013) 6 .

[66] K.K. Chadman, S.R. Guariglia, J.H. Yoo, New directions in the treatment of autism spectrum disorders from animal model research, Expert Opin Drug Discov, 7 (2012) 407-416.

[67] J.L. Silverman, M. Yang, C. Lord, J.N. Crawley, Behavioural phenotyping assays for mouse models of autism, Nat Rev Neurosci, 11 (2010) 490-502. 
[68] F. Sforazzini, A. Berterto, L. Dodero, G. David, A. Galbusera, A. Bifone, M.L. Scattoni, M.

Pasqualetti, A. Gozzi, Erratum to: Altered functional connectivity networks in acallosal and socially impaired BTBR mice, Brain Struct Funct, 221 (2016) 1207.

[69] D.M. Jones-Davis, M. Yang, E. Rider, N.C. Osbun, G.J. da Gente, J. Li, A.M. Katz, M.D. Weber, S. Sen, J. Crawley, E.H. Sherr, Quantitative trait loci for interhemispheric commissure development and social behaviors in the BTBR T(+) tf/J mouse model of autism, PLoS One, 8 (2013) e61829.

[70] M.L. Scattoni, S.U. Gandhy, L. Ricceri, J.N. Crawley, Unusual 1 nertoire of vocalizations in the BTBR T+tf/J mouse model of autism, PLoS One, 3 (2008) e3067

[71] M.L. Scattoni, A. Martire, G. Cartocci, A. Ferrante, ' Kicceri, Reduced social interaction, behavioural flexibility and BDNF signalling in the BTBk $\mathrm{T}+\mathrm{tf} / \mathrm{J}$ strain, a mouse model of autism, Behav Brain Res, 251 (2013) 35-40.

[72] D. Wahlsten, P. Metten, J.C. Crabbe, Su. vev of 21 inbred mouse strains in two laboratories reveals that BTBR $\mathrm{T} /+\mathrm{tf} / \mathrm{tf}$ has severely reduced $\mathrm{ti}_{\mathrm{i}}$ pocampal commissure and absent corpus callosum, Brain Res, 971 (2003) 47-54.

[73] M. Squillace, L. Dodero, M. Jede ici, S. Migliarini, F. Errico, F. Napolitano, P. Krashia, A. Di Maio, A. Galbusera, A. Bifone, M.L. Scattoni, M. Pasqualetti, N.B. Mercuri, A. Usiello, A. Gozzi, Dysfunctional dopaminerg 1 neurotransmission in asocial BTBR mice, Transl Psychiatry, 4 (2014) e427.

[74] B. Egaas, E. Courchesne, O. Saitoh, Reduced size of corpus callosum in autism, Arch Neurol, 52 (1995) 794-801.

[75] A.L. Alexander, J.E. Lee, M. Lazar, R. Boudos, M.B. DuBray, T.R. Oakes, J.N. Miller, J. Lu, E.K. Jeong, W.M. McMahon, E.D. Bigler, J.E. Lainhart, Diffusion tensor imaging of the corpus callosum in Autism, Neuroimage, 34 (2007) 61-73. 
[76] G. Provenzano, Z. Corradi, K. Monsorno, T. Fedrizzi, L. Ricceri, M.L. Scattoni, Y. Bozzi, Comparative Gene Expression Analysis of Two Mouse Models of Autism: Transcriptome Profiling of the BTBR and En2 (-/-) Hippocampus, Front Neurosci, 10 (2016) 396.

[77] H. Wolosker, K.N. Sheth, M. Takahashi, J.P. Mothet, R.O. Brady, Jr., C.D. Ferris, S.H. Snyder, Purification of serine racemase: biosynthesis of the neuromodulator D-serine, Proceedings of the National Academy of Sciences of the United States of America, 96 (1999) 721-725.

[78] F. Errico, M.T. Pirro, A. Affuso, P. Spinelli, M. De Felice, A. D'Aniello, R. Di Lauro, A physiological mechanism to regulate $\mathrm{D}$-aspartic acid and $\mathrm{NMD}^{\wedge}$ ㄴ.-1s in mammals revealed by $\mathrm{D}-$ aspartate oxidase deficient mice, Gene, 374 (2006) 50-57.

[79] G.E. Hardingham, H. Bading, The Yin and Yang of N " 5 A receptor signalling, Trends Neurosci, 26 (2003) 81-89.

[80] F. Errico, R. Nistico, F. Napolitano, ¿. Mazzola, D. Astone, T. Pisapia, M. Giustizieri, A. D'Aniello, N.B. Mercuri, A. Usiello, Incr ased D-aspartate brain content rescues hippocampal agerelated synaptic plasticity deterioration of ni ie, Neurobiol Aging, 32 (2011) 2229-2243.

[81] D. Punzo, F. Errico, L. Cris ino, S. Sacchi, S. Keller, C. Belardo, L. Luongo, T. Nuzzo, R. Imperatore, E. Florio, V. De N'wellis, O. Affinito, S. Migliarini, G. Maddaloni, M.J. Sisalli, M. Pasqualetti, L. Pollegioni, i vraione, L. Chiariotti, A. Usiello, Age-Related Changes in D-Aspartate Oxidase Promoter Methylation Control Extracellular D-Aspartate Levels and Prevent Precocious Cell Death during Brain Aging, J Neurosci, 36 (2016) 3064-3078.

[82] L. Cristino, L. Luongo, M. Squillace, G. Paolone, D. Mango, S. Piccinin, E. Zianni, R. Imperatore, M. Iannotta, F. Longo, F. Errico, A.L. Vescovi, M. Morari, S. Maione, F. Gardoni, R. Nistico, A. Usiello, d-Aspartate oxidase influences glutamatergic system homeostasis in mammalian brain, Neurobiol Aging, 36 (2015) 1890-1902. 
[83] A.L. Sheldon, M.B. Robinson, The role of glutamate transporters in neurodegenerative diseases and potential opportunities for intervention, Neurochem Int, 51 (2007) 333-355.

[84] T.M. Kazdoba, P.T. Leach, M. Yang, J.L. Silverman, M. Solomon, J.N. Crawley, Translational Mouse Models of Autism: Advancing Toward Pharmacological Therapeutics, Curr Top Behav Neurosci, 28 (2016) 1-52.

[85] J. Kaluzna-Czaplinska, E. Zurawicz, W. Struck, M. Markuszewski, Identification of organic acids as potential biomarkers in the urine of autistic children using gas chro atography/mass spectrometry, $\mathrm{J}$ Chromatogr B Analyt Technol Biomed Life Sci, 966 (2014) 70-7ศ

[86] A. Noto, V. Fanos, L. Barberini, D. Grapov, C. Fattuoni, M. Zaffanello, A. Casanova, G. Fenu, A. De Giacomo, M. De Angelis, C. Moretti, P. Papoff, I Ditonno, R. Francavilla, The urinary metabolomics profile of an Italian autistic children $1-\rho \mathrm{u}$ ation and their unaffected siblings, J Matern Fetal Neonatal Med, 27 Suppl 2 (2014) 46-52

[87] C. Evans, R.H. Dunstan, T. Rothkirc. T.K. Roberts, K.L. Reichelt, R. Cosford, G. Deed, L.B. Ellis, D.L. Sparkes, Altered amino acir es cr stion in children with autism, Nutr Neurosci, 11 (2008) 917.

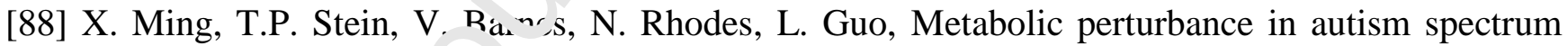
disorders: a metabolomics s. `ay, J Proteome Res, 11 (2012) 5856-5862.

[89] C. Chung, S. Ha, H. Kang, J. Lee, S.M. Um, H. Yan, Y.E. Yoo, T. Yoo, H. Jung, D. Lee, E. Lee, S. Lee, J. Kim, R. Kim, Y. Kwon, W. Kim, H. Kim, L. Duffney, D. Kim, W. Mah, H. Won, S. Mo, J.Y. Kim, C.S. Lim, B.K. Kaang, T.M. Boeckers, Y. Chung, H. Kim, Y.H. Jiang, E. Kim, Early Correction of N-Methyl-D-Aspartate Receptor Function Improves Autistic-like Social Behaviors in Adult Shank2(-/-) Mice, Biol Psychiatry, 85 (2019) 534-543. 
[90] M. Urbano, L. Okwara, P. Manser, K. Hartmann, A. Herndon, S.I. Deutsch, A trial of Dcycloserine to treat stereotypies in older adolescents and young adults with autism spectrum disorder, Clin Neuropharmacol, 37 (2014) 69-72.

[91] P.J.T.M. Yang, A Pilot Trial of Sodium Benzoate, a D-Amino Acid Oxidase Inhibitor, Added on Augmentative and Alternative Communication Intervention for Non-Communicative Children with Autism Spectrum Disorders, 6 (2017) 1-5. 


\section{Figure Legends}

Figure 1. HPLC detection of free D-aspartate and L-aspartate content in the prefrontal cortex of BTBR, Cntnap $2^{-/}$, Shank $3^{--}$and 16p11.2 $2^{+/}$mice. (a- c) Analysis of (a) D-aspartate, (b) L-aspartate levels and (c) D-/total aspartate ratio in the prefrontal cortex of BTBR and C57BL6/J strains (n=4/strain). (d-f) Amount of (d) D-aspartate, (e) L-aspartate, and (f) D-/total aspartate ratio in the prefrontal cortex of Cntnap $2^{-/}$and Cntnap $^{+/+}$mice (n=4/genotype) determined by HPLC analysis. (gi) Measurement of (g) D-aspartate, (h) L-aspartate content, and ( D-/total aspartate ratio in the prefrontal cortex of Shank $3^{-/}(\mathrm{n}=3)$ and Shank ${ }^{+/+}(\mathrm{n}=4)$ animals $(\mathbf{i}-$.$) Analysis of levels of (j) D-$ aspartate, (k) L-aspartate, and (l) D-/total Asp ratio in the pr-fro.nal cortex of $16 p 11.2^{+/-}$mutants and $16 p 11.2^{+/+}$rodents (n=4/genotype). $* p<0.05, * * * \mathrm{p}<0.06{ }^{1} 1$ ( sspin-Welch's test analysis). Values are expressed as the mean \pm SEM. All the amino acids we e $\lrcorner \epsilon^{\text {tected }}$ in a single run by HPLC and expressed as $\mathrm{nmol} / \mathrm{g}$ tissue, while the ratio is expressed os $\mathrm{p}$ rcelıage (\%).

Figure 2. HPLC detection of free D-asportc ıe and L-aspartate content in the hippocampus of BTBR, Cntnap $^{--}$, Shank $3^{--}$and $16 p 11.2^{+/}$m心o (a- c) Analysis of (a) D-aspartate, (b) L-aspartate levels and (c) D-/total aspartate ratio in he lippocampus of BTBR and C57BL6/J strains ( $\mathrm{n}=4 / \mathrm{strain})$. (d-f) Amount of (d) D-aspartar $\cong$ L-aspartate, and (f) D-/total aspartate ratio in the hippocampus of Cntnap $2^{-/}$and Cntnap $2^{+/+}$mice (n=4/genotype) determined by HPLC analysis. (g-i) Measurement of (g) D-aspartate, (h) L-aspartate content, and (i) D-/total aspartate ratio in the hippocampus of Shank $3^{-/}$ $(\mathrm{n}=3)$ and Shank ${ }^{+/+}(\mathrm{n}=4)$ animals. $(\mathrm{j}-\mathrm{l})$ Analysis of levels of (j) D-aspartate, (k) L-aspartate, and (l) D/total Asp ratio in the hippocampus of $16 p 11.2^{+/}$mutants and $16 p 11.2^{+/+}$rodents ( $\mathrm{n}=4 /$ genotype). ${ }^{*} p<0.05,{ }^{* * *} \mathrm{p}<0.0001$ (Aspin-Welch's test analysis). Values are expressed as the mean \pm SEM. All the amino acids were detected in a single run by HPLC and expressed as nmol/g tissue, while the ratio is expressed as percentage (\%). 
Figure 3. HPLC detection of free D-aspartate and L-aspartate content in the serum of BTBR, Cntnap2 ${ }^{\circ}$, Shank $3^{-/}$and $16 p 11.2^{+-}$mice. (a- c) Analysis of (a) D-aspartate, (b) L-aspartate levels and (c) D/total aspartate ratio in the serum of BTBR and C57BL6/J strains ( $n=4 /$ strain). (d-f) Amount of (d) Daspartate, (e) L-aspartate, and (f) D-/total aspartate ratio in the serum of $\mathrm{Cntnap}^{-/-}$and $\mathrm{Cntnap2}^{+/+}$mice ( $\mathrm{n}=4 /$ genotype) determined by HPLC analysis. (g-i) Measurement of (g) D-aspartate, (h) L-aspartate content, and (i) D-/total aspartate ratio in the serum of Shank3 ${ }^{-/}\left(\mathrm{n}=3\right.$, ind Shank3 ${ }^{+/+}(\mathrm{n}=4)$ animals. $(\mathbf{j}-$ I) Analysis of levels of (j) D-aspartate, (k) L-aspartate, and (1) L I* stal Asp ratio in the serum of $16 \mathrm{p} 11.2^{+/}$mutants and $16 \mathrm{p} 11.2^{+/+}$rodents ( $\mathrm{n}=4 /$ genotype). ${ }^{*}<<0.05$ (Aspin-Welch's test analysis). Values are expressed as the mean \pm SEM. All the amino ac. ${ }^{1}$ - were detected in a single run by HPLC and expressed as $\mathrm{nmol} / \mathrm{g}$ tissue, while the ratio is exp ${ }^{\circ}$, se $\mathrm{d}$ as percentage (\%).

Figure 4. L-glutamate levels in the prefruntal cortex, hippocampus, and serum of BTBR, Cntnap2 ${ }^{-1}$, Shank $3^{-/}$and $16 p 11.2^{+-}$mice. (a.e,1) Content of L-glutamate in the (a) prefrontal cortex ( $\mathrm{n}=4 /$ genotype), (e) hippocampus ( $\mathrm{n}=5 /$ genotype), and (i) serum ( $\mathrm{n}=4 /$ genotype) of BTBR and C57BL6/J mice detected bv 4P LC. (b,f,j) L-glutamate amount in the (b) prefrontal cortex (n=4/genotype), (f) hippo $n_{\iota_{1}}$ us ( $\mathrm{n}=6 /$ genotype), and (j) serum ( $\mathrm{n}=4 /$ genotype) of Cntnap $^{-/-}$and Cntnap $^{+/+}$mice. (c,g,k) Detection of L-glutamate content in the (c) prefrontal cortex $\left(\right.$Shank $^{+/+}, \mathrm{n}=4$;

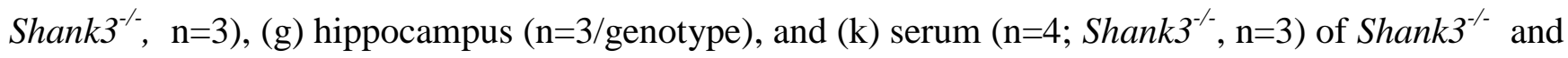
wild-type mice. (d,h,l) Levels of L-glutamate in the (d) prefrontal cortex (n=4/genotype), (h) hippocampus ( $\mathrm{n}=6 /$ genotype), and (1) serum ( $\mathrm{n}=4 /$ genotype) of $16 \mathrm{p} 11.2^{+/-}$and wild-type $16 \mathrm{p} 11.2^{+/+}$ mice. ${ }^{*} p<0.05$, compared to control group (Aspin-Welch's test). Values are expressed as the mean \pm SEM of $\mathrm{nmol} / \mathrm{g}$ tissue or $\mu \mathrm{M}$ concentrations, while the ratio is expressed as percentage (\%). 
Figure 5. Analysis of Ddo, Daao and Sr mRNA expression in the brain of BTBR, Cntnap2 ${ }^{--}$, Shank $3^{--}$, and 16p11.2 $2^{+/}$mice. (a-f) Levels of (a,d) Ddo, (b,e) Daao, and (c,f) $S r$ mRNA expression in the (a- c) prefrontal cortex and (d-f) hippocampus of BTBR and C57BL/6J mice detected by qPCR analysis (n=6/genotype). (g-l) Amount of (g,j) Ddo, (h,k) Daao, and (i,l) $S r$ transcript in the (g-i) prefrontal cortex and (j-1) hippocampus of Cntnap $2^{-/}$and Cntnap $^{+/+}$mice (n=6/genotype). (m-r) qPCR analysis of $(\mathrm{m}, \mathrm{p}) D d o$, $(\mathrm{n}, \mathrm{q})$ Daao, and (o,r) $S r$ genes in the (m-o) prefrontal cortex and (p-r) hippocampus of Shank $3^{-\%}$ and Shank $3^{+/+}$animals (n=9/genotype). (s-x) Expression levc's of (s,v) Ddo, (t,x) Daao, and $(\mathrm{u}, \mathrm{x}) \operatorname{Sr}$ genes in the (s-u) prefrontal cortex and (v-x) hipporn $\eta_{{ }_{\mathrm{r}}}{ }^{\cdots}$, of $16 p 11.2^{+/}$and $16 p 11.2^{+/+}$ $\left(\mathrm{n}=12 /\right.$ genotype). N.D. indicates that mRNA expression lev' ${ }^{\prime}$ was not detectable. mRNA expression for each single gene was normalized to the mean of two ho - ckeeping genes and expressed as $2^{-\Delta \Delta \mathrm{Ct}}$. * $p<0.05, * * p<0.01, * * * p<0,0001$ compared to $\mathrm{nt}$ ol group (unpaired t-test). All values are expressed as mean \pm SEM 
Table 2. Schematic representation of D-Asp metabolism in the prefrontal cortex, hippocampus and serum of ASD mouse models. Abbreviations: $\uparrow$, increased; $\downarrow$, decreased; =, unaltered.

\begin{tabular}{|c|c|c|c|c|c|}
\hline & \multicolumn{2}{|c|}{ Prefrontal cortex } & \multicolumn{2}{|c|}{ Hippocampus } & Serum \\
\hline ASD mouse model & D-Asp/total Asp & Ddo mRNA levels & D-Asp/total Asp & Ddo mRNA levels & D-Asp/total Asp \\
\hline BTBR & $\uparrow$ & $\downarrow$ & $\uparrow$ & $\downarrow$ & $\uparrow$ \\
\hline Cntnap $2^{-/-}$ & $=$ & $=$ & $=$ & $=$ & $=$ \\
\hline Shank3 ${ }^{-/-}$ & $=$ & $=$ & & $=$ & $=$ \\
\hline $16 \mathrm{p} 11.2^{+/-}$ & $=$ & $=$ & - & $=$ & $=$ \\
\hline
\end{tabular}




\section{CRediT author statement}

Tommaso Nuzzo: Investigation, Visualization, Formal analysis, Writing - Review \& Editing Masae Sekine: Investigation, Visualization Daniela Punzo: Investigation, Validation Mattia Miroballo: Investigation, Visualization Masumi Katane: Resources, Validation, Writing - Review \& Editing Yasuaki Saitoh: Investigation, Visualization Alberto Galbusera: Writing - Review \& Editing Massimo Pasqualetti: Writing - Review \& Editing Francesco Errico: Validation, Writing - Review \& Editing Alessandro Gozzi: Resources, Writing - Review \& Editing Jean-Pierre Mothet: Writing Review \& Editing Hiroshi Homma: Resources, Writing - Review \& Editing; Supervision Alessandro Usiello: Conceptualization, Writing - Original Draft, Supervision, Funding acquisition 


\section{Journal Pre-proof}

\section{Highlights}

- D-aspartate content was increased in the brain and serum of BTBR mice.

- Ddo mRNA levels were reduced in prefrontal cortex and hippocampus of BTBR mice.

- D-aspartate metabolism was unaltered in Cntnap2 $^{-/}$, Shank3 ${ }^{-/-}$, and $16 p 11.2^{+/}$mice.

- L-glutamate levels were augmented in the serum of BTBR mice.

- D-Ser metabolism was unaltered in BTBR, Cntnap $2^{-/}$, Shank $3^{-/}$and $16 p 11.2^{+/}$mice. 